\title{
A hospital based prospective study of acute childhood poisoning
}

\author{
G N Lucas ${ }^{1}$ \\ Sri Lanka Journal of Child Health, 2006; 35: 12-19
}

(Key words: Acute poisoning, children, hospital based study)

\begin{abstract}
Objective To study acute poisoning in Sri Lankan children.

Design A prospective hospital based study.

Setting Lady Ridgeway Hospital for Children, Colombo.

Patients Children with suspected acute poisoning admitted to hospital from January 1985 to January 2000 .

Results There were 2100 children with acute poisoning. $1256(60 \%)$ were males. $1643(78 \%)$ were below 4 years of age. Route of poisoning was ingestion in 2094 (99.7\%) cases. Household products were involved in $1050(50 \%)$ cases, drugs in 622 (30\%), poisonous plants in $212(10 \%)$, agrochemicals in $134(6 \%)$ and miscellaneous substances in 82 (4\%).
\end{abstract}

Outcome There were 14 (0.7\%) deaths.

\section{Introduction}

Poisoning is a common childhood accident but the outcome is rarely fatal ${ }^{1}$. In many instances only small quantities of the poison are actually ingested and there is uncertainty whether it will prove harmless or whether active measures should be promptly instituted $^{2}$. Childhood poisoning results from a complex interaction between the child, a hazardous substance and the environment ${ }^{3}$. Time of day, relationship to meals, accessibility of product, recent experience with the substance and family stress are some of the environmental factors involved ${ }^{3}$.

\section{${ }^{1}$ Consultant Paediatrician, Lady Ridgeway Hospital Colombo.}

(Received on 13 January 2005. Accepted on 31 March 2005).

\section{Patients and Methods}

A prospective study was carried out on children admitted to the Lady Ridgeway hospital (LRH) with suspected acute poisoning from January 1985 to January 2000, a period of 15 years. A detailed history was obtained from the parent or relative accompanying the child. A complete physical examination was done and appropriate investigations carried out. Children were observed during their hospital stay and the treatment given was noted. Those with complications were followed up in the clinic. Food poisoning and poisoning due to snake venom were specifically excluded from the study.

\section{Results}

During study period 2100 children were admitted to LRH with acute poisoning. One thousand two hundred and fifty six (60\%) were male and 844 $(40 \%)$ were female. Ages ranged from 2 weeks to 12 years. Age distribution is shown in Table 1.

Table 1

Age Distribution

\begin{tabular}{|c|c|}
\hline Age(years) & No. of children (\%) \\
\hline$<1$ & $117(05.5)$ \\
\hline $1-3$ & $1526(72.5)$ \\
\hline $4-5$ & $198(09.5)$ \\
\hline $6-12$ & $259(12.5)$ \\
\hline
\end{tabular}

The route of poisoning was ingestion in 2094 $(99.7 \%)$ cases, inhalation in 5 and dermal absorption in one case. The substances inhaled were insecticide spray, chlorine gas, anti-rust spray and petrol fumes. The dermal absorption consisted of an organophosphate insecticide.

The type of poison involved comprised household products in $1050(50 \%)$ cases, drugs in $622(30 \%)$, poisonous plants in $212(10 \%)$, agrochemicals in 134 $(6 \%)$ and miscellaneous substances in $82(4 \%)$ instances. 
Household products involved are shown in Table 2.

Table 2

Household products

\begin{tabular}{|l|c|}
\hline Household product & No. of children \\
\hline Kerosene oil & 757 \\
\hline Mosquito coils & 121 \\
\hline Turpentine & 24 \\
\hline Toilet disinfectant & 20 \\
\hline Paint thinner & 20 \\
\hline Bleaching powder & 18 \\
\hline Caustic soda & 13 \\
\hline Moth balls & 12 \\
\hline Dyes & 10 \\
\hline Detergents & 08 \\
\hline Match-heads & 06 \\
\hline Air freshener & 05 \\
\hline Eau de Cologne & 05 \\
\hline Glue & 05 \\
\hline Furniture polish & 05 \\
\hline Perfume & 04 \\
\hline Rubber paint & 03 \\
\hline Brasso & 03 \\
\hline Crayon & 03 \\
\hline Torch battery & 03 \\
\hline Rigifoam & 02 \\
\hline Polythene & 01 \\
\hline Salt-petre & 01 \\
\hline Mosquito repellent & 01 \\
\hline
\end{tabular}

Kerosene oil was the commonest household product ingested accounting for 757 cases. 6 children deliberately ingested kerosene oil after being reprimanded by their parents. One teenaged mother deliberately administered kerosene oil to her 3 week old infant after quarrelling with her husband and mother-in-law. The other 750 cases of kerosene oil poisoning were accidental. In my series 503 (67\%) children were given coconut milk to induce emesis and $387(77 \%)$ of them did vomit. 428 (57\%) children ingesting kerosene oil developed pneumonitis and were treated with antibiotics with or without steroids. $85 \%$ of the children with pneumonitis had vomited after kerosene oil ingestion. There were 4 deaths in children ingesting kerosene oil. All had vomited prior to hospital admission and were drowsy and tachypnoeic, chest $\mathrm{x}$-rays showing extensive pneumonic changes. All 4 developed pneumothorax, pneumomediastinum and pneumopericardium and died despite mechanical ventilation and intercostal drainage. 2 children with pneumonitis developed pneumatocoeles 2 weeks after kerosene oil ingestion and on follow up these disappeared within 6 months. A detailed description of the children ingesting kerosene was published in the Ceylon Journal of Child Health ${ }^{4}$.

Of the 13 children who had ingested caustic soda 2 $(15 \%)$ developed oesophageal strictures on followup.

Drugs ingested are shown in Table 3.

Table 3

Drugs ingested

\begin{tabular}{|l|c|}
\hline \multicolumn{1}{|c|}{ Drug } & No. of children \\
\hline Drugs for local use & 190 \\
\hline Anticonvulsants & 135 \\
\hline Psychiatric drugs & 122 \\
\hline Miscellaneous drugs & 165 \\
\hline Unidentified drugs & 10 \\
\hline
\end{tabular}

Drugs for local application included surgical spirits, cetrimide lotion, camphor oil, Whitfield lotion, methyl salicylate lotion and calamine lotion. Most of these substances were dispensed at the outpatients department of Lady Ridgeway Hospital into containers brought by parents, no labelling whatsoever being done. These unlabelled containers were often kept alongside the baby's cough syrup or gripe water bottle on the same shelf or table. Oculogyric crises and dystonic reactions were a frequent accompaniment of ingestion of stelazine and haloperidol and responded well to treatment with benzhexol.

Four deaths occurred in children ingesting drugs. The first death occurred in an 18 month old boy who had accidentally ingested 30 tablets of imipramine. He was unconscious with irregular respiration and was mechanically ventilated in the intensive care unit (ICU), gastric lavage being done with cuffed endotracheal tube. Subsequently he developed arrhythmias, hypotension and fits. Despite therapy he died without regaining consciousness. The second death occurred in a 10 year old girl who had deliberately ingested 43 tablets of phenobarbitone. She was deeply unconscious with irregular respiration. She was treated in the ICU with forced alkaline diuresis and mechanical ventilation but died within 24 hours. The $3^{\text {rd }}$ and 4 th deaths occurred in boys aged 4 and 5 years respectively who had accidentally ingested $10-20 \mathrm{ml}$ of methyl salicylate lotion. They became deeply unconscious with acidotic breathing and developed recurrent convulsions. Despite gastric lavage, anticonvulsants and forced alkaline diuresis, they died within 24 hours. A detailed description of drug poisoning was published in the Sri Lanka Journal of Child Health ${ }^{5}$. 
Poisonous plants ingested are shown in Table 4.

Table 4

Poisonous plants ingested

\begin{tabular}{|l|c|}
\hline \multicolumn{1}{|c|}{ Poisonous plant } & $\begin{array}{c}\text { No. of children } \\
(\%)\end{array}$ \\
\hline Jatrophus curcas & $46(22)$ \\
\hline Ricinus communis & $44(21)$ \\
\hline $\begin{array}{l}\text { Dieffenbachia/Alocasia/C } \\
\text { aladium }\end{array}$ & $31(14)$ \\
\hline Adenia palmata & $20(09)$ \\
\hline Amanita phalloides & $16(07)$ \\
\hline Manihot utilissma & $12(06)$ \\
\hline Nicotiana tabacum & $10(05)$ \\
\hline Thevetia peruviana & $10(05)$ \\
\hline Gloriosa superba & $08(04)$ \\
\hline Abrus precatorius & $08(04)$ \\
\hline Datura stramonium & $07(03)$ \\
\hline
\end{tabular}

Of poisonous plants ingested the commonest were Jatrophus curcas ('Weta endaru') and Ricinus communis ('Beheth endaru') which together accounted for 90 (43\%) cases. Features of poisoning consisted of nausea, vomiting, drowsiness, abdominal pain and diarrhoea resulting in dehydration, electrolyte imbalance and shock. Most children had ingested 1-3 seeds but a few had ingested 5-6 seeds. Except for gastric lavage and intravenous rehydration, no other therapy was given and all of them recovered uneventfully.

Poisoning with the Dieffenbachia ('Habarala') family occurred in $31(14 \%)$ cases. The children presented with itching, swelling of the lips and tongue and mouth ulceration and were treated symptomatically.

Two deaths occurred in children who had ingested poisonous plants. The first death occurred in a 5 year old boy who had eaten manioc and then drunk ginger tea. 2 hours later he started to vomit, became drowsy and developed recurrent convulsions. $\mathrm{He}$ was ventilated in the ICU but died within 48 hours. Specific antidotes were not available. The second death occurred in a 5 year old boy who had ingested Adenia palmatum ('Hondala') fruit growing wild on creepers near a paddy field. He developed high fever, vomiting, diarrhoea with blood in the stools, fits and drowsiness. Despite IV fluid therapy, blood transfusion and anticonvulsants, he died. A postmortem examination showed necrotising enteritis. A detailed description of poisonous plants ingested was published in the Indian Journal of Paediatrics $^{6}$.

Agrochemicals involved are shown in Table 5.
Table 5

Agrochemicals

\begin{tabular}{|l|c|}
\hline \multicolumn{1}{|c|}{ Agrochemical } & No. of children \\
\hline Insecticides & 84 \\
\hline Rodenticides & 43 \\
\hline Herbicides & 07 \\
\hline
\end{tabular}

Agrochemicals accounted for $6 \%$ of poisoning. There were no deaths due to ingestion of insecticides or rodenticides. Of 7 children ingesting Paraquat, a herbicide, 2 (29\%) died. In the first case, an 11 year old boy deliberately ingested Paraquat after being scolded by his father. Two days later he developed dysphagia, mouth ulceration and jaundice. Subsequently he developed subcutaneous emphysema of the neck and progressive dyspnoea and died after 5 days. In the second case, a 2 year old girl was forced to drink Paraquat by her parents, who themselves committed suicide thereafter. Despite gastric lavage and administration of Fuller's earth and mannitol, the child died after 12 hours.

The miscellaneous substances involved are shown in Table 6 .

Table 6

Miscellaneous substances

\begin{tabular}{|l|c|}
\hline \multicolumn{1}{|c|}{ Substance } & No. of children \\
\hline Petrol/Diesel & 23 \\
\hline Corrosive acids & 17 \\
\hline Alcohol & 14 \\
\hline Copper sulphate & 07 \\
\hline Mercury & 07 \\
\hline Brake oil & 03 \\
\hline Benedict solution & 02 \\
\hline Camphor pellet & 02 \\
\hline Emulsion remover & 02 \\
\hline Chlorine gas & 01 \\
\hline Car wash & 01 \\
\hline Red cement powder & 01 \\
\hline Lime water & 01 \\
\hline Anti-rust spray & 01 \\
\hline
\end{tabular}

There were 2 deaths among children ingesting miscellaneous substances. The first death occurred in a 3 year old boy who had ingested a quarter bottle of alcohol. Soon after, the child developed a fit and became drowsy. The same evening the child was admitted to hospital deeply unconscious with rightsided focal fits. He was given anticonvulsants, IV dextrose and mannitol. The CT scan was normal. Despite treatment the child died without regaining consciousness. The second death occurred in a 2 month old baby who had been mistakenly 
administered acetic acid by the mother instead of gripe water, both bottles being on the same table.

\section{Discussion}

The male: female ratio was $3: 2$. The male predominance seen in my study is a feature common to most series of childhood poisoning ${ }^{3} .1643(78 \%)$ children were under 4 years of age. It is only at 4 years that children understand simple safety rules and have enough good sense not to eat everything they come across ${ }^{3}$. Thus, in my series, self-control through education could have acted as a primary deterrent to poisoning in only $22 \%$ of cases. Parents should strive for complete and instant obedience to rules of safety early in the child's life. It is much better to go through life with a questionably scarred ego than a very real scarred oesophagus requiring a lifetime of repeated dilatations.

Drugs account for over one half of reported poisoning in Germany, France, Italy, America, England and Canada ${ }^{3}$. In one survey, the average home had 30 containers of medication $^{3}$. In less well-developed countries, the substances ingested reflect the toxic substances in the home. For instance, in India, kerosene oil used for heating is a principal toxin, in one study accounting for $60 \%$ of all poisoning ${ }^{7}$. In my series drugs accounted for only $30 \%$, household products accounting for $50 \%$ of poisoning episodes.

Kerosene oil ingestion was the leading cause of poisoning in Sri Lankan children, accounting for 36\% of the total. The frequency of kerosene oil poisoning can be attributed to several factors. Firstly, kerosene oil is stored in almost every home. Secondly, kerosene oil containers are often kept in easily accessible places such as the kitchen floor, a low table or a low shelf and are hardly ever stoppered. Thirdly, due to its colour, children often mistake kerosene oil for bottled soft drinks. In kerosene oil poisoning there are 2 major pathological effects, an irritative effect on alveolar walls of the lungs with rapid development of a chemical pneumonitis and a depressing effect on the brain from absorption of toxic material from the alimentary and respiratory $\operatorname{tracts}^{8}$. In Sri Lanka mothers frequently induce vomiting with coconut milk given to the child immediately after kerosene ingestion. Vomiting predisposes to aspiration. The dangers of inducing emesis after kerosene oil ingestion should be widely publicized. Since kerosene oil has a bad taste, large volumes are rarely ingested but, due to its low surface tension and high vapour pressure, entry of even a few $\mathrm{ml}$ of kerosene oil into the airways will result in a severe pneumonitis $^{8}$.

Ingestion of pieces of mosquito coils accounted for $6 \%$ of poisoning. Fortunately, these contain low concentrations of pyrethrins or synthetic pyrethroids and their toxicity is low because of poor absorption via the gastrointestinal tract ${ }^{9}$. No treatment was considered necessary.

Drugs for local application were often kept in unlabelled containers alongside the baby's medicine. It is thus not surprising that most of these substances were mistakenly administered to the child by an adult. At least a red warning label should be affixed to these containers indicating that such preparations should not be taken orally.

Anticonvulsants and psychiatric drugs are usually prescribed on a fortnightly or monthly basis so that they are available in bulk in the house. Furthermore, children see adults taking these drugs on a regular basis and tend to imitate them. Thus, it is not surprising that these drugs were so frequently ingested by children. It is not certain that colouring and sugar coating play a decisive part in accidental poisoning. However, it is unwise to add attractions to tablets known to be harmful. For instance, a toddler had ingested 20 paracetamol tablets of the lozenge type. A sweet taste may be more dangerous than colour ${ }^{8}$.

Seeds of 'Weta endaru' and 'Beheth endaru' contain the glycoproteins 'curcin' and 'ricin' which are responsible for the toxicity ${ }^{10,11}$. They have an irritant effect on the gastrointestinal mucosa and it is said that ingestion of 26 seeds may be fatal ${ }^{11}$. Although a few children in my series had ingested 5-6 seeds there were no fatalities. The intense vomiting, which was almost always present following ingestion, is probably responsible for the minimal toxicity in my patients.

All parts of plants of the 'Habarala' family contain calcium oxalate crystals. On ingestion, the crystals pierce the tender tissues of the mouth causing intense pain and swelling ${ }^{12}$. The roots and leaves of Manihot utilissma ('Manioc') contain a cyanogenic glycoside linamarin and an enzyme linase. Ginger contains a factor which is capable of releasing hydrocyanic acid from the glycoside ${ }^{13}$. The close resemblance of the 'Hondala' fruit to passion fruit is responsible for accidental poisoning among children. The fruit contains a cyanogenic glycoside, a toxalbumin and an enzyme emulsin which could release free hydrocyanic acid from the glycoside ${ }^{14}$. Necrotising enteritis is due to the local effects of the toxalbumin.

Poison control centres have been established worldwide to provide information to the physician on the ingredients, toxicity, expected symptomatology and recommended therapy in cases of acute poisoning resulting from ingestion of a multitude of household products and pharmaceuticals ${ }^{3}$. In Sri Lanka a national poisons information centre has been established in the National Hospital, Colombo since 1988 and provides information on poisoning 24 hours a day, throughout the year. 
The only measure, definitely shown to reduce the incidence of childhood poisoning, is the use of childresistant containers. Scherz, in an American study, reduced the number of poisoning episodes in a local community from 149 to 17 by the use of such containers $^{15}$. A multicentre study has shown that in addition to child-resistant containers, opaque blister packs, strip packs and sachets were less associated with poisoning episodes whereas transparent blister packs were more dangerous ${ }^{3}$. However, safer packaging is not a substitute for parental vigilance, child guidance or safe storage principles. It offers an additional measure of safety at little or no additional expenditure of thought or effort by the parent. Safer packaging can be applied to pharmaceuticals, household products and agrochemicals. In Sri Lanka, there is a place for dispensing psychiatric drugs and anticonvulsants in child-resistant containers.

Another method of poison prevention used in the USA is the poison-warning sticker displaying a green scowling face with a protruding tongue and the emergency telephone number of the local poison centre $^{15}$. The stickers are placed on the containers of hazardous substances in the home to discourage children from handling these containers or ingesting their contents. However, one controlled trial found that poison prevention stickers may not deter toddlers from manipulating labelled poisons ${ }^{16}$.

It is important that prescriptions are properly labelled giving the name and strength of the drug. This will facilitate identification of drug in an emergency situation such as accidental poisoning and also minimize chances of a mix-up of medicines at home.

The wide variety of poisons ingested by the preschool child indicates that he will ingest any substance clearly visible to him and easily accessible. In my series, lack of adult supervision together with careless storage and disposal of toxic substances were the chief factors responsible for accidental poisoning in the preschool child.

The pattern of poisoning among school children was different. $33 \%$ of the school children had deliberately ingested poison, more an act of defiance than a true suicidal attempt. Only 2 of these children died. About $55 \%$ of the school children had ingested poisonous plants due to mistaken identification. The remainder had ingested poison due to a mix-up of medicines because of non-labelling of bottles.

Family stress is an important factor in accidental ingestion of poisons in childhood ${ }^{17,18}$. It may make poisons readily available to children either because parents under stress are less careful or because medicines are being used during an illness. Another possibility is that the child's behaviour is altered when there is unhappiness in the home with disordered family relationships. In addition, children may wish to medicate themselves, imitating their parents.

Poisoning is related to the development pattern of child ${ }^{3}$. The 6 month old child will put any object into the mouth. A 1-2 year old child will experimentally taste most things. By the time he is $2-3$ years old, the child has access to any unlocked drawer or cupboard in the home. The 4 year old child is more selective in what is ingested, preferring those that taste good. In my series, kerosene oil, which has a bad taste, was ingested almost entirely by the 1-3 year age group.

Sobel and Margolis compared 20 poison repeaters with 19 single ingestors and 13 controls on a variety of factors ${ }^{19}$. They concluded that repetitive poisoning in children seems to result from purposeful behaviour on the part of the child. Correlated with this behaviour were hyperactivity, negativism and other behaviour problems of the child, limited parent-child relationships, marital tension and a tense and distant family atmosphere. In my series, there were 6 poison repeaters.

Childhood poisoning deaths are uncommon. In my series, there were 14 deaths giving a mortality rate of $0.7 \%$. Of the deaths 2 were cases of suicide, 2 were homicides and 10 were accidental.

In conclusion, I would like to suggest some measures which may help to reduce the incidence as well as the morbidity and mortality of childhood poisoning in Sri Lanka.

1. Keep kerosene oil containers tightly stoppered and out of reach of children.

2. Do not store kerosene oil in soft drink bottles.

3. Publicize the dangers of inducing emesis following kerosene oil ingestion.

4. Keep agrochemicals under lock and key.

5. Educate the people regarding disposal of unused medicine. Do not throw unused tablets on to the garden or road.

6. Advise parents not to ingest medicine in front of children as they are great imitators. Always read the label on the bottle before giving medicine.

7. Label all medicine and fix red warning labels on bottles containing preparations for local use.

8. Do not store medicine in gripe water bottles and cough syrup bottles, as by so doing mistakes are bound to occur. 
9. Educate school children in all aspects of childhood poisoning.

10. Advise drug manufacturers to desist from making drugs more attractive to children.

11. Keep toddlers under strict supervision as accidental poisoning chiefly occurs in this age group.

12. Dispense drugs prescribed on a fortnightly or monthly basis, such as psychiatric drugs and anticonvulsants in child-resistant containers.

\section{Acknowledgements}

I thank the Consultant Paediatricians of the Lady Ridgeway Hospital for allowing me access to children under their care for this study. I also thank the registrars and house officers of the respective paediatric medical units for their ungrudging cooperation.

\section{References}

1. Fraser N C. Accidental poisoning deaths in British children 1958-77. British Medical Journal 1980; 280: $1595-8$.

2. Verhulst H L, Crotty J J. Childhood poisoning accidents. Journal of American Medical Association 1968; 203: 145-6.

3. Scherz R G. Prevention of childhood poisoning: A community project. Paediatric Clinics of North America 1970; 17(3): 713-27.

4. Lucas G N. Kerosene oil poisoning - the direful predicament of the Sri Lankan toddler. Ceylon Journal of Child Health 1992; 21: 9-16.

5. Lucas G N. Acute drug poisoning in children. Sri Lanka Journal of Child Health 2000; 29: 45-8.

6. Lucas G N. Plant poisoning: A hospital-based study in Sri Lanka. Indian Journal of Paediatrics 1992; 64: 495-502.

7. Buharwella $\mathrm{R}$ J, Sanjanwalla. Poisoning in children, a study of 303 cases. Indian Paediatrics 1969; 6: 141-5.

8. Klein B L. Hydrocarbon poisonings. Paediatric Clinics of North America 1986; 33: 411-9.
9. Fernando R. Management of pesticide poisoning. Colombo: The Pesticides Association of Sri Lanka, 1988; 14-15.

10. Abdu-Aguye I, Sannusi A, Alafiya-Tayo R A, Bhusnurmath S R. Acute toxicity studies with Jatropha curcas. Human Toxicology 1986; 5: 26974.

11. Kinamore $\mathrm{T}$ A. Abrus and Ricinus ingestion : Management of 3 cases. Clinical Toxicology 1980; 17: 401 .

12. Drach G, Maloney W H. Toxicity of the common house plant Dieffenbachia. Journal of the American Medical Association 1963; 184: 1047-8.

13. Kodagoda N, Marcus V, Ambalavaner S. Some observations on the liberation of hydrogen cyanide from manioc. Proceedings of the Annual Sessions of the Sri Lanka Association for the Advancement of Science 1973; 1: 38.

14. Munasinghe D R, Karunanayake A, Nimalasuriya A, Kodagoda N. Poisoning with Adenia palmata. Ceylon Medical Journal 1971; 16: 182-6.

15. Scherz R G, Latham G H, Stracener C E. Childresistant containers can prevent poisoning. Pediatrics 1969; 43:84.

16. Vernberg K, Culver Dickinson P, Spyker D A. The deterrent effect of poison-warning stickers. American Journal of Diseases in Children 1984; 138: $1018-20$.

17. Sibert J R. Stress in families of children who have ingested poisons. British Medical Journal 1975; 3: 87-9.

18. Sobel R. The psychiatric implications of accidental poisoning in childhood. Paediatric Clinics of North America 1970: 17: 653-85.

19. Sobel R, Margolis J. Repetitive poisoning in children: A psychosocial study. Pediatrics 1965; 35: 641 . 
